\title{
Perspectivas de los acuerdos de limitación y desarme en América Latina y el Caribe
}

El presente trabajo, de acuerdo al tema asignado por FLAcso, tiene por objeto analizar la vigencia y perspectivas de los acuerdos regionales de limitación y desarme y proponer una alternativa de solución para su estudio e investigación. El énfasis ha sido puesto en las posibilidades de poner en marcha la reciente propuesta del presi. dente peruano A'an García, dando continuidad a la Declaración de Ayacucho, rescatando sus logros, actualizando sus lecciones y tratan do así de desarrollar una iniciativa para América del Sur.

El trabajo sigue la secuencia siguiente: Objetivo: poner en marcha un acuerdo regional; el significado moderno de seguridad; un procedimiento para la reducción del gasto; antecedentes regionales para reducir el gasto militar; el caso de Centroamérica y el Caribe; la propuesta Alan García; un enfoque para desarrollar la iniciativa García; consideraciones finales.

\section{OвJETIVo: Poner en marcha un acuerdo regional de reducción del gasto militar.}

La América Latina atraviesa una crisis sin precedentes en su historia, caracterizada por su extrema agudeza, por su enorme deuda externa y por la adversidad de los factores financieros $y / o$ comerciales externos. Asimismo, experimenta una severa disminución en el ingreso per capita, el cual ha llegado a retroceder a niveles de diez años atrás y más de la cuarta parte de su población económicamente act va está inmersa en la desocupación.

La región se enfrenta cada día a una serie de problemas urgentes que tienen importancia decisiva para el bienestar, tales como el desarrollo y la búsqueda de un nuevo orden internacional justo. La carrera de armamentos con su costo y sus implicancias políticas es vista como un obstáculo para alcanzar este bienestar. La pobreza, el hambre, las condiciones sanitarias, la falta de vivienda, el desempleo, y apropiados niveles de educación, tienen proporciones dramáticas en muchas partes de América Latina. Estos problemas 
exigen inversiones que se consideran postergadas por los gastos de adquisiciones de armamentos. Los gastos militares cuantiosos tienden a agravar la inflación, complican los problemas ya existentes de balanza de pagos y prolongan la recesión y el desempleo. Debido a estos gastos excesivos, añadidos al servicio de la enorme deuda externa y las imposiciones recesivas del FMI, los gobiernos no d'sponen de espacio económico para morerse y políticamente se hacen más vulnerables.

Sólo recientemente se está prestanđo atención a la relación entre los gastos militares y desarme, por una parte, y los aspectos del desarrollo social, económico y polftico, por la otra, como lo hace el Informe Brandt. La Organización de Estados Americanos, el Grupo Andino, la CEPAL, SELA, han omitido el análisis de las consecuencias de la carrera de armamentos en el desarrollo socio-económico. Los efectos económicos de la reducción de gastos militares, del desarme, serán beneficiosos, dado que liberarían recursos materiales, financieros y humanos internos que permitirán asignarlos a propósitos del desarrollo y aliviar la crisis. Esto no se discute. Creemos que lo que realmente está en discusión y debería ser materia de un acuerdo previo, a nivel regional mundial, es sobre ¿dónde reside el problema? ¿Cuáles son los mecanismos fundamentales de la carrera de armamentos? ¿Cuáles son los procedimientos más prácticos y realistas para disminuir los gastos militares? ¿Qué tipo de control internacional se requiere para que las medidas por adoptarse resulten eficaces? ¿Cómo formular una campaña de difusión, para preparar la opinión pública? En tanto a nivel sudamericano no se elabore un marco global, alcanzado por consenso, que delinee claramente los puntos de vista de la comunidad internaciona! sobre estos y otros interrogantes, se fije una estrategia coherente y se determine un tipo de control internacional, no será fácil la adopción de medidas realistas y concretas sobre el desarme. Estimamos que lo más avanzado y ambicioso elaborado recientemente sobre "control militar", después de la Declaración de Ayacucho, es lo establecido en el Acta Revisada de Contadora presentada en septiembre del Secretario de la oNU, lamentablemente congelada por maniobras políticas de la Administración Reagan, y sobre cuyos aspectos volveremos más adelante.

Por su naturaleza misma, el problema del desarme es de una envergadura mundial y a solucionarlo debe responder la estructura de las Naciones Unidas. Un sistema regional de desarme sólo tendrá un valor complementario y no debe pensarse sobre bases subregionales menores. La Declaración de Ayacucho no prosperó porque su ámbito estuvo referido a los países del Grupo Andino. Debido a la crisis centroamericana y a los planteamientos en marcha para soluc:onarla, las características especiales de México y de los países de 
la Cuenca del Caribe, América del Sur requiere un tratamiento se. parado. En el contexto del desarme a esta parte del continente bien cabría atribuírsele el concepto de región debido a los efectos en cadena que históricamente suscita en su ámbito la compra de armamentos y la índole de las medidas que deberán adoptarse.

Por tratarse de aspectos vitales que afectan recíprocamente el interés nacional de más de dos países, ya que cada país tiene una realidad vecinal distinta, en la determinación de una opción sobre limitación o congelación de los gastos militares, tal como la planteada por el Presidente peruano, el marco geográfico más apropiado, como mínimo, debe ser Sudamérica en su conjunto, pues, además los problemas que obstaculizan el progreso en materia de desarme son en gran medida de naturaleza regional sudamericana distinta a Centroamérica y el Caribe. Resulta evidente entonces que una de las primeras tareas será definir exactamente el ámbito geográfico de aplicación de las medidas. Entretanto será necesario perfeccionar los mecanismos de las Naciones Unidas, la Organización de los Estados Americanos, SELA y el Grupo Andino, para avanzar en el campo de la reducción de los gastos militares. Para lograrlo no se requiere una mera construcción jurídica, sino la voluntad política basada en la realidad internacional y en la aspiración ciudadana, la que debe ser cultivada.

La característica actual de la carrera de armamentos está en la "dinámica de los cambios cualitativos", los que la estimulan, impulsan y complican los esfuerzos por controlarla. La carrera de armamentos entre las grandes potencias es de índole predominantemente cualitativa, característica que igualmente se está haciendo presente en América del Sur. Los sistemas de armas convencionales se perfeccionan y cambian constantemente en tamaño, potencia de fuegos, velocidad, propulsión, exactitud, versatilidad. La comisión de expertos de las Naciones Unidas en su informe de 1977 manifiesta que "la indole cualitativa de la carrera de armamentos en su centro constituye así una de las fuerzas principales que impulsan la proliferación horizontal ace'erada de las armas convencionales". Tal hecho ya está ocurriendo en América del Sur con la carrera emprendida para dotar a sus Fuerzas Armadas de la misilería de más alta tecnología.

Para que el desarme sea eficaz será necesario actuar simultáneamente en dos vertientes: en la reducción de los gastos militares y en la limitación de la carrera cualitativa de armamentos, aspecto éste al que debe darse prioridad máxima, por ser la tarea más apremiante de nuestra época y que corresponde a las grandes potencias, por ser ellas quienes producen el variado surtido de armas estratégicas convencionales, nucleares y sus sistemas vectores.

Por tal razón estimamos pertinente para Sudamérica, enfocar el 
problema básicamente desde estos puntos de vista: a) El campo de la reducción de los gastos militares y el de la prohibición de armas ofensivas sofisticadas vía congelación de las adquisiciones por un lapso razonable, planteamiento nuevo y más realista de los ya conocidos, que aspira a la disminución del riesgo de guerra y simultáneamente al mejoramiento del desarrollo y la seguridad nacional y regional. b) Crear un sistema que permita la verificación y control del proceso.

El objetivo de Sudamérica debe ser poner en marcha un acuerdo regional de reducción de los gastos militares y la prohibición de la fabricación y emplazamiento de artefactos nucleares, con la finalidad de promover la seguridad regional y nacional y contribuir a la distensión de los conflictos. La situación internacional de esta parte del continente, a diferencia del contexto mundial, y los procesos de consolidación de las democracias hacen propicia la ocasión para un acuerdo de esta naturaleza. Por ello resulta en extremo importante evitar que se emprendan acciones precipitadas que puedan hacer inalcanzable dicho objetivo. Las relaciones internacionales después de los sucesos de Afganistán, El Líbano, Centroamérica, se encuentran en una especie de encrucijada que conducirá bien a la cooperación o bien a los recelos recíprocos y la consecuente intensificación de la carrera armamentista.

Para tratar directamente con los acreedores el problema de la deuda y enfrentar al FMI, reactivar la economía, mejorar las condiciones de empleo, incrementar las exportaciones, detener la expansión de la propagación de la onda explosiva social y la violencia insurgente, resulta cada vez más realista reducir los elevados montos en adquisiciones militares mediante compromisos de reciprocidad.

\section{El significado moderno de la seguridad}

Los problemas de seguridad de un país están íntimamente ligados al desarrollo del mismo, de manera que a nivel político, no resulta posible tratarlos como fenómenos independientes. La seguridad requiere un proceso continuo de desarrollo y en todo caso al estadista corresponde alcanzar los objetivos nacionales sin detrimento de una o de otra. Los gastos militares, pues, no deben afectar el desarrollo de un país, porque su estancamiento o retroceso atenta contra la seguridad. A mayor desarrollo, mayor seguritad. La finalidad de la Seguridad Nacional consiste, en esencia, en proporcionar a la nación un grado de garantía para alcanzar el desarrollo; su significado es mucho más amplio y menos restringido a los aspectos puramente militares.

Las medidas para alcanzar la reducción de los gastos militares deberán ser tomadas de manera tal que no afecten la Seguridad Na- 
cional de cada una de las naciones implicadas. Para que tengan éxito las medidas de reducción de los gastos militares, su cumplimiento en función precisamente del desarrollo, debe dar a las partes contratantes una sensación de mayor seguridad, y deberán favorecer la mutua confianza. Podría pues sentarse como premisa que el objetivo principal para intentar acuerdos vía reducción de gastos militares, es en fin de cuentas mejorar la seguridad nacional. La reducción de los gastos militares deberá pues basarse sobre el derecho legítimo a la seguridad.

Otro objetivo común a la reducción de gastos militares es contribuir a la solución de las diferencias básicas que dan lugar a los conflictos y las tensiones internacionales, de manera de promover la paz y la estabilidad en la región. En la actualidad, las relaciones entre paises de América Latina se hallan ensombrecidas por la existencia de problemas no resueltos. Si se lograse un grado de cooperación para obtener una reducción en los gastos militares, quizás, aquella podría extenderse al terreno de los problemas y tensiones políticas. En todo caso, es previsible que una reducción en los gastos militares iría paralela con el Iogro de un clima político mucho más propicio a la solución de dichos problemas.

A su vez las soluciones políticas y la supresión de las causas del conflicto, como el reciente acuerdo del Beagle, facilitarán las negociaciones sobre reducción de gastos militares; sin embargo, debido a la urgencia no podemos considerar que una eliminación substancial de los conflictos potenciales en América Iatina sea la condición necesaria para progresar en el camino de la reducción de los gastos militares. No obstante, estimamos que el reciente arreglo del Beagle, que abre una nueva etapa de cooperación entre Chile y Argentina y la tácita congelación de los conflictos entre Venezuela y Colombia y Venezuela-Guyana, en razón de que la actual crisis centroamericana impone a dichos países una conducta más prudente, favorecen la iniciativa peruana de Alan García, del 28 de julio de 1985, para retomar la iniciativa de Ayacucho a nivel sudamericano.

A lo largo de la historia y hasta el momento actual subsiste el supuesto subyacente de que la guerra es un recurso legítimo del que pueden echar mano los Estados en sus relaciones recfprocas para la solución de sus diferendos. Este es el sentido de la famosa frase de Clausewitz: "la guerra es simplemente la continuación, por otros medios, de la política".

Esta frase, era el trasunto del "realismo político" tal como se conoce desde Maquiavelo y que el Derecho Internacional, a pesar de sus disposiciones, no ha podido eliminar. La carrera armamentista es una causa de la guerra; su competencia exacerba, a veces, una situación política en tensión, que a su vez ha sido la causa primordial de dicha carrera. 
Un desarme sin reciprocidad, haría de los países vec:nos del país que se desarme, o de cualquier país, los únicos jueces de sus actos para declarar y hacer la guerra y la nación que se desarme unilateralmente no estaria en condiciones de preservar ciertos intereses $y$ aspiraciones que todo Estado tiene que proteger, en virtud de su calidad de entidad política soberana. Un adversario armado, no puede ser derrotado con estallidos emociona?es o con prédicas de moral internacional. Es mucho lo que cuesta la ignorancia de la seguridad. La cuenta no se paga en dinero, sino con la vida de la juventud en el campo de batalla y la mutilación del territorio nacional.

Para hacer frente a la eventualidad de un conflicto, en tanto no se alcance un acuerdo global sudamericano de disminución en los gastos militares, pues no se puede hablar de nivel latinoamericano mientras subsista la crisis centroamericana, la doctrina estratégica procura como idea central alcanzar la disuasión. La disuasión es en esencia una actitud defensiva, una amenaza de llevar a cabo una acción punitiva en el caso que se torne inminente la acción contra la cual la amenaza está apuntada. Para ser creíble la amenaza es preciso que la nación esté "decidida" para su realización. Debe señalarse que la frecuencia de la guerra, desde la Edad Media, demuestra la dificultad de lograr la disuasión, al menos en el campo de la guerra convencional.

Por el momento en América del Sur, el mantenimiento de fuerzas disuasivas se considera como el mejor instrumento para garantizar la estabilidad existente. Se estima que estas fuerzas disuasivas no deberán reducirse unilateralmente mientras no se haya creado un mecanismo que imponga la paz y asegure el orden, la ley y la justicia internacional. De otro lado, el mundo entero es una unidad política en la política internacional. En consecuencia, deberá buscarse, primero, adecuados y seguros medios internacionales para imponer la paz. Abogamos por que los recursos monetarios se empleen únicamente para el desarrollo; pero sería suicida hacerlo sin bases de reciprocidad. Entretanto puede resultar irresponsable alentar las esperanzas para alcanzar una meta irrealista.

\section{Un procedimiento para la reducción del gasto}

La Asamblea General de las Naciones Unidas, en la década del 70, adoptó diferentes medidas con el propósito de avanzar en la senda del desarme, como el valioso documento emitido en 1978. En los informes preparados por los grupos de expertos en 1974 y 1976 se aprecia ya la adopción de un nuevo procedimiento, a saber, el logro del desarme por medio de la reducción de los gastos militares. Este procedimiento contrasta con los anteriores esquemas de desar- 
me - "Iimitación de armamentos" y "control de armamentos"- pues lo enfoca desde un punto de vista económico y financiero, en valores monetarios en función precisamente del desarrollo, y no desde el punto de vista del número y naturaleza del armamento, de valor inestable y' gran versatilidad tecnológica.

Además de la gran desconfianza que existe entre los Estados para obtener una reducción en los gastos militares que redunde en un efectivo desarme $y$ en un valioso aporte para la paz, se presenta el problema de la carencia $y$ desigualdad de las informaciones disponibles. Los informes de 1974 y 1976, elaborados por sendos grupos de expertos, se concretan fundamentalmente a tratar de resolver este segundo problema, previo a toda futura negociación sobre desarme mediante el tratamiento de las tres áreas siguientes:

a) Definición del "gasto militar" y del "sector militar". Al respecto existe una considerable divergencia entre los diferentes Estados y para salvarla se requiere previamente la homologación de las cuentas militares. La mayoría de los Estados incluyen dentro del sector militar y, por tanto, consideran como "gasto militar" a rubros que desde el punto de vista de la finalidad que se busca no necesariamente deben considerarse, tales como: pagos a personal civil, sueldos y pensiones militares, operaciones de acción cívica, etc. Es necesario, pues, comenzar por hablar un lenguaje común que identifique los alcances del "sector militar" y precise lo que debe considerarse como "gasto militar".

El informe del segundo grupo de expertos, en 1976, definió lo que debe considerarse "gastos militares" y formuló una matriz que se sugiere como base de un patrón internacional de contabilidad militar. En la matriz de doble entrada aparece en una columna el Grupo de Fuerzas y en la otra hilera los Costos de Recursos. Asi:

- El Grupo de Fuerzas se descompone en: fuerzas estratégicas, de fines generales, de apoyo, paramilitares, defensa civil y asistencia militar.

- El costo de los Recursos contiene tres grandes rubros: Gastos de Funcionamiento: Adquisiciones y Construcciones, e Investigación y Desarrollo.

b) Formulación de un presupuesto militar tipo de vigencia internacional. Este paso requiere la utilización por los páses de un modelo o formato especial, para cuentas militares, de tal modo que permita la homologación y la comparación de los gastos militares. Para dicho efecto serviria la matriz descrita, la que podría ser particularmente útil, para comenzar a establecer la comparación internacional del gasto militar, sin lo cual resulta poco menos que factible las negociaciones para la adopción de este nuevo procedimiento. 
Es sabido que muchos países en América Latina disponen de cuentas especiales para la defensa nacional y que no se incluyen en los presupuestos militares. Se afirma, sin que esto nos conste, que Chile tiene permanentemente abierta una cuenta en bancos fuera del país, proveniente de la venta del cobre, para adquisiciones militares cuyo empleo es inmediato y le proporciona mayor flexibilidad. Es probable que la parte de los ingresos que obtiene el Ecuador de su petróleo y que están asignados a su defensa nacional, tenga el mismo tratamiento. En todo caso estos sistemas crean la desconfianza, que por lo demás está presente cualquiera que sean los esquemas por adoptar para alcanzar un efectivo desarme.

c) Valuación del gasto militar. Como el procedimiento se basa en la reducción de los gastos militares, las negociaciones buscarán, en la medida de lo posible, conseguir reducciones equivalentes entre sí y que reflejan deducciones comprobables de los potenciales militares. Para dicho efecto los expertos proponen la utilización de la conocida técnica de los números índice, la que está sujeta a considerables limitaciones aplicada al valor de bienes y servicios que podrían obtenerse si los recursos se trasladan del sector militar al civil.

Los informes de las comisiones de expertos de 1974 y 1976, no son excluyentes de otras aproximaciones metodológicas y constituyen un procedimiento integral teóricamente complejo, destinado a determinar cómo realizar las reducciones en los gastos de armamen. tos y de esta manera disminuir el peligro de la guerra y contribuir al afianzamiento de la paz. Muchos institutos de investigación en la materia vienen empleando la definición de la NATO sobre lo que se entiende por gastos militares que incluyen: los gastos corrientes y de capital de las Fuerzas Armadas y otros órganos encargados de proyectos de la defensa; el costo de las fuerzas paramilitares y policiales cuando éstas son entrenadas y equipadas para operaciones militares; los costos de investigación y desarrollo y las pruebas de evaluaciones; el costo de las pensiones de retiro de los miembros de las Fuerzas Armadas, incluyendo las de personal civil. Sin embargo, muchos problemas se encuentran al emplear esta definición debido a la ausencia de gastos desagregados; la incertidumbre sobre la inclusión de la ayuda militar externa en los presupuestos; el nivel en que las fuerzas policiales $y$ las fuerzas de guardacostas juegan un verdadero rol militar.

Gomo ejemplo de lo difícil que puede resultar el que los paises sudamericanos nos pongamos a debatir sobre qué aspectos debemos incluir como gastos militares, señalamos el reciente trabajo de investigación peruano: Impacto económico del gasto de defensa 19701980, hecho por los investigadores Oscar Dancuartt y Adolfo Figueroa, en donde analizan cinco distintas series de importaciones de

$$
\left[\begin{array}{lll}
4 & 6 & ]
\end{array}\right.
$$


armas, con sus respectivas fuentes. Dadas las diferencias existentes, como ellos afirman, el problema consiste entonces en averiguar cuál de ellas es la más confiable.

Por ello, estimamos la conveniencia de iniciar un proceso gradual para abordar las posibilidades de un acuerdo de limitación de gastos militares, sobre la base de la Declaración de Ayacucho y la reciente Declaración de Lima, para lo cual estimamos necesario comenzar con el compromiso de la constitución de por lo menos dos Grupos de Trabajo Sudamericanos con la finalidad de formular un lenguaje común, analizar la situación actual de dichos gastos y proponer planteamientos concretos, simples $y$ viables, que ayuden a nuestros gobiernos en la apertura del diálogo y la negociación sobre dicha materia.

Cualquier procedimiento que se analice para la reducción del gasto en armamentos en la región, tendrá que ser enfocado teniendo en cuenta un escenario con nuevas y distintas tendencias, cuyas principales caracterfisticas, en resumen, presenten el cuadro siguiente:

1. En tanto que la década del 70, en lo que a compra de arma* mentos se refiere, América del Sur se caracteriza por el fortaleci-

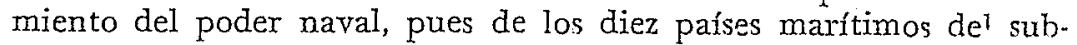
continente, ocho adquirieron submarinos modernos $y$ cuatro de ellos fragatas lanzamisiles de nueva construcción; la década del ochenta se caracteriza por el ingreso definitivo de la región a la era de los misiles. La guerra de las Malvinas demostró la necesidad de reforzar las fuerzas navales en su defensa antimisil y antiaérea con Exocet, de fortalecer Ios sistemas de misiles tierra-aire de las fuerzas terrestres y de dotar a las fuerzas aéreas particularmente de misiles aire-buque. En efecto, en los últimos tres años han adquirido: Brasil 48 Exocet (misiles buque-buque); Chile 8 Exocet, un número indeterminado de Rapier y 16 Seacat; Argentina 168 Exocet y 96 Aspide; Colombia 32 Exocet y 64 Seasparrow; Ecuador 36 Exocet y 72 Aspide; y Perú 40 Exocet, 96 Otemat.

Desde el punto de vista de una eventual negociación sobre limitación de gastos militares, la carrera de los misiles introduce un factor de perturbación, pues, como el Presidente chileno la insinúa, cualquiera negociación debe hacerse a base de las armas mayores, pero resulta que por ejemplo un tanque mediano es un arma mayor, cuyo costo está muy por debajo de un Rapier o de un Exocet, los que tienen mucho más poder destructivo; sin embargo, a estos últimos generalmente no se les incluyen en el concepto de armas pesadas o mayores. Por tales razones estimamos que uno de los temas a formar parte de cualquier agenda para un acuerdo regional de limitación de armamentos, deberá comenzar por definir qué tìpos de la generación de misiles se incluyen como armas mayores. 
2. En los últimos años en América Latina se están produciendo cambios importantes en las adquisiciones de equipo y materiales bélicos y fabricación de los mismos. En efecto, se ha comenzado a adquirir los modelos más recientes de armamentos convencionales. La compra más significativa es la de los Exocet MM 40 por casi todos los países; la realizada por Venezuela a EE. UU. de 24 aviones F.16 a un costo de 615 millones de dólares, venta hecha según el Departamento de Estado debido a la "subversión dirigida por Cuba y la creciente presencia militar soviética en el 'Caribe", recientemente este país ha instalado un sistema de misiles en sus fronteras; y la de los M'rage 2000 hecho por el Perú a Francia, reducidos recientemente a 13. Ha disminuido apreciablemente la compra de equipos de segunda mano y excedentes por la rapidez en que se vuelven obsoletos; se prefiere el abastecimiento de diversas fuentes de producción para romper las ataduras de la dependencia del proveedor único en materia de repuestos y municiones. Los abastecedores tradicionales: EE. UU., IngIaterra y Francia han dejado de tener preferencia, ya no teniendo el primero el monopolio de proveedor de la región. La compra de armas ya no se hace en función de bloques, alineamientos de Fuerzas o zonas de influencia. Esta evolución marca una mayor autonomía militar y política de América Latina respecto a los abastecedores y cierra un ciclo en el que a través del TIAR, EE. UU. buscó la estandarización de armas y equipos en su tradicional zona de influencia.

3. Paralelamente a esta situación no podemos dejar de mencionar dos hechos nuevos y significativos: la región se ha convertido en la década del 80 en un incesante y expansivo mercado exportador $y$ eficiente competidor, a escala mundial, en la fabricación y comercio de armamentos, incluyendo los de tipo sofisticado. Un segundo hecho es la crisis de Gentroamérica como un eslabón del conflicto Este-Oeste y por tanto escenario competitivo de abastecimiento "desinteresado" de armas por las grandes potencias en procura de sus propios fines. Desde el punto de vista de una negociación sobre limitación de gastos en armamento, resultan igualmente factores de perturbación el creciente proceso de desarrollo de las industrias militares en la región y la crisis centroamericana.

\section{Antecedentes regionales para reducir el gasto militar de armas convencionales}

En la región han tenido lugar diversas y múltiples iniciativas y propuestas para reducir los gastos militares. Los antecedentes más lejanos se encuentran en las tratativas peruano-colombianas de $1831 \mathrm{y}$ 1849, mediante las que ambos países habrian acordado la reducción de sus fuerzas militares y limitado los efectivos militares permitidos 
en zonas fronterizas, y las conversaciones chileno-argentinas de 1881 que culminaron con la desmilitarización del Estrecho de Magallanes.

Pero por haber dado lugar a las primeras negociaciones multilaterales al más alto nivel técnico realizadas en América Latina con la participación de expertos de las Fuerzas Armadas entre países, muchos de ellos, hasta ayer tradicionales adversarios y constituir una coordenada de referencia histórica para cualquier tratamiento futuro, el antecedente más importante es, sin duda alguna, la Declaración de Ayacucho suscrita en 1974, a iniciativa del Perú, por Argentina, Bolivia y Chile, Colombia, Ecuador, Panamá, Perú y Venezuela y reafirmada en 1978. Las partes firmantes de esta Declaración se comprometieron a promover y a sostener la construcción de un orden duradero de paz internacional y de cooperación, y crear las condiciones que permitan una efectiva limitación de armamentos, poniendo fin a su adquisición con propósitos ofensivos, para dedicar los recursos liberados al desarrollo económico y social de los pueblos. Se acordó, así, un paso inicial para hacer efectiva la reducción de gastos militares.

La importancia de la Declaración de Ayacucho no debe verse únicamente en su contenido declarativo introductorio de aspiración para buscar la reducción del gasto militar con la finalidad de dedicar todos los recursos posibles al desarrollo social y económico de América Latina, sino en el hecho poco conocido del trabajo espectfico que como consecuencia de ella se realizó después, mediante una serie de reuniones de carácter técnico durante los años 1975 y 1976.

La primera reunión de expertos se llevó a cabo en Lima, formalizándose un debate general y estableciéndose una secretaría protempore, con la que se dio inicio al estudio del acercamiento metodológico al tema, buscando previamente un lenguaje común mediante la definición de conceptos, la identificación de procedimientos de limitación en los gastos militares y de medidas de verificación y control. Una segunda reunión tuvo lugar en Santiago, en la que después de coincidirse en la necesidad de crear un clima de confianza en la opinión pública e iniciar la cooperación entre instituciones militares, se crearon tres grupos de trabajo que se dedicaron a estudiar especificamente los aspectos siguientes: cooperación entre los institutos armados, limitación de armamentos, determinación de parámetros económicos y uniformización de presupuestos militares, y posibilidades de fijar ciertos límites máximos a algunos tipos de armamentos. Dichos grupos realizaron reuniones en Santiago, Lima y Caracas, respectivamente.

Como resultado concreto de dichos trabajos, en 1975 los representantes de Bolivia, Colombia, Ecuador, Perú y Venezuela formularon a sus gobiemos la primera recomendación en la materia, en el sentido de que cualquier futuro acuerdo sobre limitación de arma- 
mentos debería incluir la prohibición de armas ofensivas altamente sofisticadas, cuya adquisición podría perturbar la paz en la región. Como algo rescatable para las eventuales conversaciones que surjan como consecuencia de la propuesta García, conviene recordar lo que dichos grupos de trabajo precisaron en la mencionada categoría: armas biológicas, químicas y tóxicas, armas de energía nuclear, armas capaces de alterar el equilibrio ecológico, portaaviones de ataque, todos los sistemas balísticos teledirigidos y de largo alcance, al igual que las bombas de alto poder.

A via de experiencia es interesante señalar que, particularmente en la segunda reunión de expertos de Santiago, se puso énfasis, sin que se alcanzara consenso, en las siguientes armas posibles de ser incluidas en la categoria de prohibidas: misiles teledirigidos con un alcance superior a $40 \mathrm{Km}$.; tanques equipados con armas mayores de $105 \mathrm{~mm}$; toda la artillería superior al calibre $155 \mathrm{~mm}$. Además se analizaron los bombarderos de todo tipo, cruceros y submarinos nucleares.

Simultáneamente con las tratativas que diera lugar la Declaración de Ayacucho, las fuerzas armadas de Bolivia, Chile y el Perú, se reunieron a iniciativa de este último en tres oportunidades y en Santiago, 1976, los altos mandos de dichas fuerzas suscribieron un "Acuerdo de Cooperación para el Afianzamiento de la Paz y la Amistad entre las Fuerzas Armadas de las Repúblicas de Bolivia, Chile y Perú", en el que se establece reuniones de consulta y se abre la información militar, incluyendo el ámbito de las zonas de fronteras. En estas reuniones se planteó, como una posibilidad que podría ser estudiada, la reducción de los efectivos militares en las áreas fronterizas, al parecer, para descartar el temor recíproco a un ataque por sorpresa. Se dio a esta idea el nombre de "zonas de amortiguación" y se precisó claramente que ellas sólo podrían llevarse a efecto por acuerdos bilaterales de los Estados directamente interesados.

Los mismos signatarios reiteraron en Washington, 1978, la necesidad de intensificar los esfuerzos para promover el establecimiento de condiciones conducentes a una limitación efectiva de armamentos, en orden de dedicar todos los recursos posibles al desarrollo económico y social en cada país de América Latina.

A pesar del intenso trabajo desplegado y del alto nivel técnico y polf́tico de los negociadores, lamentablemente los resultados no se tradujeron en acuerdos concretos. La iniciativa de Alan Garcia, como él mismo lo dice - "recogiendo el espíritu de la Declaración de Ayacucho de 1974"- tiene en estos trabajos ya realizados una base de partida ya elaborada, a condición que se sepa aprovechar sus lecciones. Creemos que las conversaciones no prosperaron por los tres motivos siguientes: 
- Se cayó en el énfasis académico, tendencia proclive en este tipo de tratativas, cuando como en nuestro caso se pierde su sentido pragmático de disminuir el gasto. El Academismo consistió en darle al término "limitación de armamentos" su más amplio sentido, con la ambiciosa meta de abordarlo todo. Así, se examinaron medidas con el propósito de limitar o abolir categorfas especificas de armas, que constriñen o prohíben el uso de determinadas armas en la guerra; que reducen el riesgo de guerra; que previenen ciertas acciones militares; que creen condiciones para un mayor acercamiento entre los Estados en el terreno militar; que eliminen las causas de la desconfianza, del temor, la tirastez y la hostilidad.

- Su marco geográfico fue reducido e impreciso, lo que dio lugar a que los alcances de lo tratado y los eventuales acuerdos se presentaran indefinidos sobre si deberían referirse al ámbito latinoamericano, sudamericano o al andino en particular.

- El alto nivel de tensión que vivió América Latina al finalizar la década del 70 y comienzos del 80 , como consecuencia de las infructuosas negociaciones colombo-venezolanas sobre limitación de la plataforma submarina en el golfo Maracaibo; el fracaso de las negociaciones para la solución al problema de la mediterraneidad de Bolivia; el estancamiento de la mediación papal en el conflicto del Beagle, entre Argentina y Chile; los incidentes militares en la cordillera El Góndor, entre Perú y Ecuador, y la agudización del problema fronterizo entre Guyana y Venezuela. Esta situación generó una evidente falta de voluntad política para alcanzar un acuerdo en la materia.

No es un eufemismo de la hora actual dar continuidad a las negociaciones de Ayacucho, reverdeciendo sus inmaduros frutos, para reducir el costo de la carrera armamentista, tanto por lo que supone en términos de paliar las tensiones como por las circunstancias de crisis generalizada que vive América Latina, en la que los reiterados aumentos de las tasas de interés y la carga de la deuda, están taciendo inviable el desarrollo y con ello creando un escenario nada propicio para la estabilidad política en la región.

Otro antecedente reciente, muy importante, es la reunión informal de Tlatelolco, en 1978, a iniciativa de México, con la participación de los representantes de América Latina y el Caribe, convocada para tratar el control de armamentos en la región. Como conclusión, se sometió a los gobiernos las siguientes bases para un diálogo futuro, pero sin resultados:

a) Establecimiento de un mecanismo de consulta flexible.

b) Propiciar a través de dicho mecanismo: Estudio y recomendación sobre la posible limitación de las transferencias de cierto tipo 
de armas convencionales hacia la región. Estudio y recomendaciones para el establecimiento de limitaciones y/o prohibiciones en el caso de cierto tipo de armas convencionales, consideradas excesivamente rıocivas $\mathrm{y} / \mathrm{o}$ de efectos indiscriminados; y servir de foro de intercam. bio de puntos de vista sobre otros temas relacionados con las negociaciones del desarme.

Los gobiernos de Costa Rica y Ecuador se ofrecieron como sedes para continuar estas negociaciones, pero conflictos regionales frustraron estas posibilidades.

No podemos dejar de reseñar que América Latina es la única región del mundo donde se aplica un régimen de no proliferación de armas nucleares a todo un continente habitado. En 1967, veinticinco naciones latinoamericanas firmaron el Tratado de Tlatelolco, habiéndolo ratificado todos, menos Argentina. Brasil y Chile han declarado que no lo considerarán en vigor hasta que todos los firmantes lo hayan hecho ya. Por el momento el Tratado no obliga a cinco países, puesto que Cuba y Guyana no lo firmaron. EE. UU., Francia, Gran Bretaña y Holanda han firmado el Protocolo $I$, que los compromete a aceptar las restricciones del Tratado respecto al emplazamiento y almacenamiento de armas nucleares. Los dos primeros lo han hecho sólo para territorios de los que son internacionalmente responsables. Gran Bretaña, China, Francia, la URSs y EE. uU. han firmado el Protocolo II por el que se comprometen a no utilizar ni amenazar con armas nucleares a los miembros del Tratado.

\section{El caso de Centroamérica y el Caribe}

Consideramos que desde el punto de vista de la estrategia para alcanzar un acuerdo de limitación de armas en Latinoamérica, deberíamos impulsar inicialmente la iniciativa Alan García para el ámbito sudamericano, propiciando paralelamente para Gentroamérica que entre en vigencia la propuesta Contadora, puesto que en materia de seguridad ésta ha logrado plasmar planteamientos prácticos muy positivos y avanzados, que sólo esperan su puesta en ejecución mediante un proceso político-diplomático en marcha.

EI Acta de Contadora para la paz y la cooperación en Centroamérica, negociada por los cinco países centroamericanos con la mediación de Contadora, fue presentada recientemente (septiembre 1985) al Secretario General de la ONU, y dada a publicidad.

El Acta establece que las partes deben adoptar medidas orientadas hacia el establecimiento o perfeccionamiento de sistemas democráticos representativos y pluralistas, y promover urgentemente acciones de reconciliación nacional. Para controlar estos acuerdos se crearán una comisión de verificación y control en materia de segu- 
ridad y un comité para la evaluación y seguimiento de los compromisos en materia política.

La implementación de los compromisos de seguridad prevé dos etapas:

En la primera, las partes se comprometen a suspender desde la firma del Acta toda adquisición de equipo bélico (excepto reposiciones, municiones y repuestos) y a no incrementar sus efectivos militares, mientras se establecen los límites máximos a partir de sugerencias de la comisión de verificación y control. En la segunda, transcurridos 60 días de la firma. las partes establecerán dentro de los 30 días los límites máximos de los tipos de armamentos y de los efectivos e instalaciones militares de los que cada parte pueda disponer. El Acta de Paz establece que ningún Estado tendrá como objetivo la búsqueda de la hegemonía de sus Fuerzas Armadas sobre los demás estados considerados individualmente.

En cuanto al Caribe, los gastos militares de los paises que lo conforman, salvo Cuba, son insignificantes. De otro lado su gravitación estratégica sale del marco regional para proyectarse geopolíticamente en el escenario mundial de la confrontación Este-Oeste. Consecuentemente, por el momento resultaría poco práctico incluirlo como parte de las tratativas de un acuerdo regional.

\section{La propuesta Alan Garcia}

El Presidente Alan García, en su mensaje a la nación peruana el 28 de julio de 1985, con ocasión de la transmisión del mando, hizo un llamado hacia un acuerdo regional, expresando:

"Por creer que la nación, su historia y su bandera tienen su asiento corporal en el pueblo, en su mayoría necesitada y urgida, creemos que mejor destino tendrán nuestros escasos recursos en la reactivación de nuestra economía y en el bienestar de nuestros pueblos, garantizando así la defensa integral de nuestra población y nuestro territorio por nuestro bienestar. Por eso, como otros gobernantes lo han hecho, invoco la necesidad de un acuerdo regional para la reducción de los gastos de armas y para el congelamiento de sus ad. quisiciones, recogiendo así el espíritu de la Declaración de Ayacucho firmada en 1974:".

$\mathrm{Y}$ pasando de las palabras y los buenos propósitos a las acciones y a los ejemplos, anunció a los pueblos latinoamericanos su decisión de:

"Reducir sustancialmente las compras de material bélico comenzando por el recorte del número de aviones Mírage cuya compra actualmente está en trámite". 
Para celebrar con el pueblo peruano la transferencia democrática del mando en el Perú, el 29 de julio, los Jefes de Estado de Argentina, Bolivia, Colombia, Panamá, República Dominicana y Uruguay, y los Representantes Especiales de Brasil, Chile, Costa Rica, Cuba, Ecuador, El Salvador, Guatemala, Haití, Honduras, México, Nicaragua, Paraguay y Venezuela, firmaron la Declaración de Lima, en uno de cuyos acápites pertinentes se expresa que:

"Consideran positiva y conveniente la reducción equilibrada de gastos militares y la asignación de mayores recursos para el desarrollo socio-económico de sus países y acuerdan promover la adopción de medidas adicionales de fomento de la confianza en la región y particularmente entre países vecinos".

Alan García prosiguió en su propuesta de reducción sustantiva de los gastos en armas en América Latina. En las recientes sesiones de las Naciones Unidas, 1985, puntualizó que:

"Cada bala que en 99\% de los casos se usa en prácticas de tiro, es - una ración alimenticia que hemos podido entregar a un niño para defenderlo de la muerte".

Repudió a los promotores de la muerte y ratificó su anuncio de que Perú ha reducido radicalmente la compra de aviones de guerra de alta sofisticación pactada con Francia y añadió que por propia iniciativa de la Marina de Guerra:

"Hemos desmontado naves armadas, y nuestras Fuerzas Armadas en el contexto de un mundo nuevo se orientan al desarrollo".

La propuesta de Alan Garcfa ha tenido en la región reacciones inmediatas favorables al más alto nivel, situación que demuestra la existencia de un clima favorable para concretar dicho planteamiento en mecanismos viables en un acuerdo de alcances regionales. En efecto:

Argentina ha reaccionado favorablemente, manifestando la Cancillerfa de ese país que ha tomado conciencia de la propuesta peruana y que expresa su coincidencia. Esta reacción es concordante con las declaraciones del Canciller Dante Caputo en la Conferencia sobre Desarme que se realizó en Ginebra y las Declaraciones formuladas por el Presidente Alfonsín en las reuniones sostenidas con mandatarios de la India, Grecia y Alemania Federal. Asi, el 18 de agosto en Bonn afirmó que:

"Su gobierno redujo a la mitad los presupuestos militares y redujo los efectivos desde que tomó el poder hace dos años".

Sin embargo, respecto a la reacción chilena, notas periodísticas argentinas dejan traslucir que Ia implementación del desarme en América Latina se dificulta por la falta de s:nceridad en las intenciones expresadas. 
Brasil no ha hecho pronunciamiento oficial en este sentido. Sin embargo trascendió que durante las negociaciones de las recientes "Declaraciones de Lima", con relación al párrafo gastos militares, cuya propuesta inicial incluía el término "congelamiento", la declaración brasileña adoptó una posición menos receptiva, que trasunta la nueva mentalidad de país exportador de armas, lo que necesariamente no significa que Brasil se abstenga de cooperar al llamado del Presidente peruano de reducir los gastos de defensa.

Colombia ha recibido favorablemente la idea de limitar los gastos militares y reducción de armamentos a nivel mundial y regional. Ha presentado a la Asamblea General de la OEA una propuesta que ha sido aprobada, en la que recomienda al Secretario General el estudio de los mecanismos y modos de lograr la reducción antes mencionada. Recientemente, a mediados de febrero de 1986, en la visita a Lima efectuada por el Canciller colombiano, Augusto Ramírez Ocampo, quedó ratificado el apoyo de Colombia a la limitación de gastos en armamentos en la región, para liberar los recursos destinándolos al desarrollo. Se acuerda realizar reuniones para la cooperación castrense.

Chile ha manifestado pública y oficialmente lo siguiente:

"Chile acoge y respalda tales planteamientos. En el mismo esp1ritu, declaramos que, en la medida en que las otras naciones de la región recojan también esta iniciativa - con idéntica generosidad y buena fe- Chile se abstendrá de adquirir nuevo material de guerra, dentro del sistema de armas mayores"

Sin embargo, en declaraciones de prensa formuladas por el Comandante en Jefe de la Armada y Miembro de la Junta de Gobierno Almirante José Toribio Merino en torno a la iniciativa del Presidente del Perú para limitar el gasto en armamentos, manifestó lo siguiente:

"Chile está dispuesto a cooperar en esa historia. Congelar significa mantenerse en el nivel similar de nuestros vecinos. Perú tiene en estos momentos 38 buques de guerra y nosotros no más de 12. Así es que hay una diferencia bastante sustancial". Precisó luego que "eso será cuando estemos 38-38, pero por ahora no estamos congelados, porque es como estar jugando un partido de fútbol en que un equipo tiene los once jugadores y el otro apenas seis, y ahí nos va a ir mal". Posteriormente dijo que "previo a un acuerdo de limitación de armas en Latinoamérica es necesario el cumplimiento del Tratado de Tlatelolco sobre proscripción nuclear" y agregó que "Argentina no lo ha ratificado".

El Ministro de Marina del Perú expresó en relación a estas declaraciones, lo siguiente: 
"Me parece que hubo un error de tipografía en las cifras recibidas. Chile tiene cerca de 42 naves de guerra. De manera que en cantidad de naves estamos totalmente equiparados".

Pero lo más relevante, sin duda alguna, han sido las reuniones de trabajo en Arica y Lima de los Ministros de Relaciones Exteriores Allan Wagner, de Perú, y Jaime del Valle, de Chile, que se concretaron en sendos comunicados cuyos párrafos pertinentes transcribimos:

Comunicado de Arica del 9 de noviembre de 1985.

"Animados por el espíritu de la Declaración de Ayacucho y con el propósito de desarrollar la iniciativa del Presidente del Perú para la concertación de un acuerdo regional sobre limitación de gastos en armamentos, que ha sido compartido por el Presidente de Chile, Ios Cancilleres reafirman la prioritaria importancia que los respectivos Gobiernos conceden a impulsar ese objetivo en el plano bilateral o regional".

Comunicado de Lima del 29 de noviembre de 1985.

"Iniciar conversaciones destinadas a obtener una limitación de gastos en adquisiciones de armamentos, fomento de la confianza mutua y desarrollo de una concepción de seguridad que responda a una estrecha amistad y creciente cooperación entre ambas naciones".

En Ecuador se ha difundido ampliamente la propuesta peruana con comentarios favorables de la prensa, a excepción de los pronunciamientos del General (R) Richelieu Levoyer. En comunicado de prensa efectuado recientemente, el Presidente de la República manifestó Io siguiente, en relación a la propuesta peruana:

"Como planteamiento de orden general, el planteamiento del nuevo Presidente del Perú merece todo el apoyo del Presidente ecuatoriano, pero el Ecuador, como país soberano, tiene que mantener sus fuerzas armadas actualizadas, no solamente desde el punto de vista del frente externo, sino también desde el punto de vista de la seguridad nacional interna del país. Hoy día, el equipo de armamento a nivel mundial es muy sofisticado, la tecnología varía de año en año, y hay que mantenerlo actualizado. Nosotros estamos por todas las tesis que impliquen reducción de gastos de armamentos, en tanto en cuanto no se nos pida que reduzcamos nuestro nivel de defensa externa e interna, más allá de los niveles que le interesa al pais".

Recientemente, el 3 de octubre pasado, el Ganciller peruano Allan Wagner anunció que Perú y Chile darán inicio a principios de mayo a las conversaciones oficiales sobre limitación bilateral de armamento, a fin de establecer pautas que promocionen un acuerdo regional de reducción del gasto militar. 
Un análisis de las reacciones suscitadas por la propuesta peruana nos permite precisar brevemente los comentarios siguientes:

Los países más directamente interesados en el tema, en términos generales, han reaccionado favorablemente con ciertas condiciones. Ast, Chile sienta como premisa que su cooperación en la iniciativa queda supeditada a la actitud que sobre ella tengan los demás pafses de la región, Io cual significa que su adhesión final dependerá de si hay o no consenso; cabe resaltar al respecto que el error ma. yor de los debates dedicados al desarme en las sesiones de las $\mathrm{Na-}$ ciones Unidas, ha consistido en insistir que los programas de desarme tenían que hacerse por consenso. Asimismo se aprecia la insistencia en señalar como prerequisito procurar el cumplimiento del Tratado de Tlatelolco, lo que entraña cautela hacia Argentina. Pero lo que hace meditar en que la eventual implementación del llamado tendiente a reducir y congelar el gasto militar se dificulta, son las expresiones del Almirante chileno citado, que ensombrece las declaraciones del propio General Pinochet y siembra dudas sobre las verdaderas intenciones de Chile, al utilizar la escopeta de dos cañones. Sin embargo, cabe recordar que Merino asumió análoga actitud en el diferendo del Beagle y que a pesar de ello éste se firmó: la posición de Chile será pues la que finalmente el General Pinochet decida.

Ecuador, en su comunicado elaborado cuidadosamente para no despertar recelos en su público interno, expresa estar dispuesto a participar en tanto las reducciones no vayan más allá de los niveles que interese al país. En otros términos, razonablemente condiciona su participación a que nada de lo que se haga afecte su doctrina de defensa ni signifique el abandono de su conçepción estratégica disuasiva, a la cual se ha aferrado por años.

El Perú ha programado diferentes acuerdos sobre limitación del gasto militar o fue parte de ellos y no participa en carrera armamentista alguna. No obstante, estima que la urgencia social de nuestros países nos impone una nueva actitud frente al exceso en los gastos de armamentos. Si no estamos en condiciones de pagar la deuda tampoco debemos usarla en beneficio de los traficantes de la muerte. Debemos ser conscientes de que el estancamiento en que ha caído el desarrollo de América Latina, el proteccionismo, y los ajustes del FMr, más allá de las suspicacias regionales, nos exige una solidaridad militante frente al enemigo común que ha acampado en toda la América morena sin respetar fronteras, con su secuela de miseria, desempleo, dependencia e injusticia social que amenaza la estabilidad política. Como resultado concreto, una reunión informal o preliminar de altos jefes de las Fuerzas Armadas del Perú y Chile, se realizará en Lima en mayo de 1986. 


\section{Un enfoque para desarrollar la iniciativa peruana}

Los pueblos están deseosos de llegar a un acuerdo sobre reducción del gasto militar y los políticos reconocen la necesidad y urgencia de concertarlo. 'Con la agudización de la crisis ha aflorado nuevamente el propósito de dar atención a esta necesidad. Un procedimiento quizás inédito para la región, simple, efectivo y de resultados inmediatos, podrfa ser optar por la congelación equilibrada de los gastos, absteniéndose de adquirir nuevo material de guerra dentro del sistema de armas mayores, excepto reposiciones, repuestos, municiones y armas menores en un lapso a ser acordado, cuyo plazo oscilaria entre 3 ó 5 años. Las características de la crisis económica que se sufre y la creciente insatisfacción social que se acrecienta, hace aconsejable adoptar procedimientos expeditos, pragmáticos y flexibles.

Congelar significa permanecer en el nivel alcanzado. Este nivel tiene dos situaciones: el armamento actualmente disponible en cada país o el que se disponga al iniciar las eventuales negociaciones, y el contratado, en vías de ser entregado y por lo tanto no está aún en manos de los usuarios. Negociar sobre lo que actualmente dispone cada pafs no concurriría al fin primordial propuesto-disminuir el gasto militar para aplicarlo a fines de desarrollo-. Negociar sobre las adquisiciones programas a futuro, contratadas pero aún no entregadas, superando los aspectos legales que ello probablemente implique, sometiéndolas a un proceso de verificación, enfocándolas desde un punto de vista económico-financiero y traducidas en reducción efectiva en valores monetarios, sí significaría un apreciable ahorro para ser transferido a obras de binestar y desarrollo.

Una propuesta a eștudiarse sería pues la posibilidad de congelar equilibradamente las compras a futuro programadas y contratadas pero aứn no entregadas, incluyendo las fabricaciones militares.

De acuerdo con los datos de la Agencia Norteamericana para el control de armas y desarme, como ya ha sido expuesto, América del Sur gastó en adquisiciones de armas en el quinquenio 1979-83 la cantidad de 7.650 millones de dólares. Otra alternativa dentro del mismo criterio podría ser el compromiso a negociar la reducción equilibrada del gasto para el quinquenio $1986-90$ en el $50 \%$ del monto gastado del quinquenio precedente, siempre negociando el congelamiento de las compras de armas mayores ya ordenadas pero aún no recibidas, porque de lo contrario se trabajaría sobre supuestos o bases subjetivas irreales.

Para hacer viable el análisis de esta propuesta se ha confeccionado exprofesamente el Anexo: "Registro de las transacciones de América del Sur 1984", adjunto, cuya información tendrá que ser confirmada. En él se puede observar que está en proceso de negociación o 
aún no ha sido recibido el armamento siguiente: Argentina 200 tanques ligeros Cruisier, 19 helicópteros A 5-322, 126 Exocet MM 40; Bolivia 12 cazas Mirage 50; Brasil 12 helicópteros UH-60, A; Chile 18 cazas Jaguar, 6 helicópteros Lynx, 100 transportadores blindados de personal, un número indeterminado de misiles móviles tierra-aire tipo Rapier; Colombia 10 aviones militares de transporte PG-6 A Porter, un número indeterminado de misiles Seasparrow; Ecuador 12 misiles Aspide tierra-buque, una corbeta clase Esmeralda; Paraguay 10 aviones militares de transporte EMB 110, indeterminado número de carros blindados de personal EE-1I Urutu; Perú 80 tanques medianos TAM, 26 Mirage 2.000 (reducido a 13), 24 misiles Aspide de diferente tipo, 12 helicópteros MI 24 Hind-D; Venezuela un número indeterminado de tanques ligeros AMX-13-90, 10 helicópteros $109 \mathrm{Hi-}$ rundo, dos buques de desembarco tipo Tacama. La experiencia de este tipo de acuerdos demuestra que ellos son efectivos en tanto se Ilegue a establecer un sistema que permita verificar y controlar el proceso de reducción equilibrada del gasto militar. Para ello será necesario crear una comisión sudamericana de verificación y control de los acuerdos a que se llegue.

Las guerras árabe-israelí de 1973 y la de las Malvinas de 1981 demostraron la velocidad con que se consumen los stocks y la preponderancia del flujo de los abastecimientos si los otros factores del poder permanecen igualmente equiparables. El Estado que es más autosuficiente en el abastecimiento de suministros de guerra debe ser clasificado como potencialmente más poderoso. Por tanto una propuesta de congelación equilibrada en los gastos militares tendria que ir aparejada paralelamente con el cese del impulso al desarrollo de las industrias militares.

Estimamos que en este aspecto pueden surgir las mayores dificultades para un acuerdo, debido a que Brasil, Argentina y Chile han superado largamente en el desarrollo de la industria militar a los demás pałses de la región y estarían en condiciones de autoproveerse de material bélico. Brasil cuenta con industrias militares de todo tipo. Es el principal exportador de América Latina y el quinto en el mundo, con ingresos en este rubro que se aproximan a Ios dos mil millones de dólares anuales. Argentina dispone de fábricas y astilleros de todo tipo de armas, municiones, equipos de campaña, buques, submarinos y aviones, y cuenta con tecnología suficiente para fabricar a corto plazo reactores nucleares para submarinos. Chile está ingresando rápidamente en el mercado internacional de ventas de armas, habiendo superado en 1975 el valor de sus exportaciones los cien millones de dólares. Cuenta con la Empresa Nacional Aeronáutica, que produce aviones de entrenamiento tácticos y se halla muy avanzado en la construcción de helicópteros, fabrica blindados, y las industrias CARDOEN S. A. han desarrollado diferen- 
tes tipos de armas y municiones, como las conocidas bombas de racimo de 500 libras.

Además la propuesta de congelamiento, extensiva al campo de la producción militar, implicaría otra dificultad: la del control y verificación de su cumplimiento, dado que una industria militar puede estar dispersa a lo largo y ancho de cada país y formar parte constitutiva de la industria privada de tiempo de paz para transformarse con elementales reajustes en industria militar en época de guerra.

\section{Consideraciones finales}

Finalmente, concluiremos afirmando que después de esporádicos intentos de limitar los gastos militares, los esfuerzos han resultado insuficientes. En realidad la región no se preocupa por buscar los métodos que permitan su reducción. Esta responsabilidad ha dejado de ser exclusiva de los cuerpos profesionales y es una tarea de todos. Hay que poner en marcha la propuesta García para la reducción del gasto militar y dar así continuidad y cumplimiento a la Declaración de Ayacucho. El proceso de compra de armamentos se aceleró en la etapa del conflicto del Beagle, y la crisis de América Latina aconseja formas más económicas y democráticas de defensa que en realidad acrecientan la seguridad.

Estados Unidos tratará de recuperar el monopolio que tuvo de "proveedor de la región". Las grandes potencias continuarán vendiendo armas en la región para fortalecer sus propias políticas externas y los Estados Unidos, además, lo hará para mantener los "equilibrios estratégicos regionales". A pesar del aumento creciente de las compras, América Latina, especialmente Brasil, Ghile y Argentina continuarán incrementando la producción y exportación de armamentos en el espacio de bajo interés para las grandes potencias, lo que eventualmente incidirá en los tradicionales equilibrios regionales. América Latina por primera vez enfrenta el riesgo de una amenaza nuclear debido a los avances logxados por Argentina y Brasil. Si así lo desean, podrán fabricar armas nucleares en la década del 80.

El futuro de América Latina depende no sólo del equilibrio militar, sino de la cooperación regional y la vocación de integración.

El armamentismo y la reducción de los gastos militares son problemas cada vez más complejos y el resultado de una multiplicidad de factores, que hace poco manejable la búsqueda de una solución a nivel latinoamericano, lo que obliga a ser prudente en su tratamiento. En un intento de solución, resumimos su enfoque en los lineamientos siguientes: 
Edgardo Mercado Jarrin / Perspectivas de los acuerdos de limitación y...

- Como primer paso poner en movimiento la Declaración de Ayacucho.

- Por razones prácticas, en una primera etapa promoverlo a nivel sudamericano.

- Dialogar y negociar sobre la base de suspender o congelar la compra de armamento mayor, incluyendo el incremento de la industria militar por un lapso razonable de 3 a 5 años. Iniciar la negociación tomando como referencia las compras ya ordenadas $y$ en proceso de entrega.

- Enfocarlo desde un punto de vista económico y financiero en valores monetarios en función del desarrollo.

- Crear un sistema de veruficación y control.

- Paralelamente apoyar para América Central y el Caribe la puesta en ejecución de los planteamientos de Seguridad del Acta aprobada de Contadora.

Es evidente que si se pudiera reducir los gastos militares en América Latina, ahorrando recursos para orientarlos al desarrollo, se incrementaría la seguridad regional y se podrían elevar los niveles de vida de las masas que hoy viven marginadas.

- Informe Naciones Unidas de 1977 $y$ documento $A / 35 / 916$ de 1981 del mismo organismo.

- Gastos Militares y Desarrollo en América del Sur. Centro de Investigaciones Económicas $\mathrm{y}$ Sociales. Universidad de Lima. 1980.

- Sipri Yearbook 1978. Instituto de Investigación para la Paz de Estocolmo.

- Sipri Yearbook 1985.

- Edgardo Mercado Jarrín, "Armamentismo en América Latina", en: Nueva Sociedad, No 59, marzoabril 1982.
- Edgardo Mercado Jarrín, "Comparación de los gastos de defensa", en: Estudios Geopoliticos y Estratégicos, No 4, mayo 1980.

- Cable de Associated Press, publicado por el diario "El Comercio", el 19 de septiembre de 1985. Fuente norteamericana. Probablemente la fuente sea el estudio anual de la Agencia estadounidense para el control de armas y desarme para dicho año.

- Recortes de periódico: fuente abierta. 
GUADRO NO 1

Compra de misiles en Sudamérica recibidos y por entregar, 1984. Confeccionado por el autor. Fuente Sipri Yearbook, 1985.
Registro de las principales transacciones de América del Sur, 1984. Confeccionado por el autor. Fuente Sipri Yearbook 1985. 
Cuadro 1

COMPRA DE MISILES EN SUDAMERICA RECIBIDOS Y POR ENTREGAR - 1984

\begin{tabular}{|c|c|c|c|c|c|c|c|}
\hline Pals & $\begin{array}{l}\text { Canti- } \\
\text { dad }\end{array}$ & Tipo de arma & Descripción & $\begin{array}{l}\text { Año de } \\
\text { orden }\end{array}$ & $\begin{array}{c}\text { Affo } \\
\text { entrega }\end{array}$ & $\begin{array}{l}\text { Cantidad } \\
\text { entregada }\end{array}$ & Comentarios \\
\hline BOLIVIA & - & $\longrightarrow$ & & - & - & - & -- \\
\hline BRASIL & $(48)$ & MM-40 Exocet & $\begin{array}{l}\text { Misiles buque- } \\
\text { buque }\end{array}$ & 1984 & & & $\begin{array}{l}\text { Para armar } 4 \text { corbetas y } \\
\text { fragatas. }\end{array}$ \\
\hline CHILE & $\begin{array}{l}(8) \\
- \\
(16)\end{array}$ & $\begin{array}{l}\text { MM- } 88 \text { Exocet } \\
\text { Rapier } \\
\text { Seacat }\end{array}$ & $\begin{array}{l}\text { Misiles buque-buque } \\
\text { Misiles móviles } \\
\text { tierra-aire } \\
\text { Msiles buque-aire y } \\
\text { buque-buque }\end{array}$ & $\begin{array}{l}1981 \\
(1985) \\
1981\end{array}$ & $\begin{array}{l}1982 \\
- \\
1982 \\
1984\end{array}$ & $\begin{array}{l}(4) \\
- \\
(8) \\
(8)\end{array}$ & $\begin{array}{l}\text { Para armar dos destroyers. } \\
\text { En negociación. } \\
\text { Para armar dos destroyers. }\end{array}$ \\
\hline ARGENTINA & $\begin{array}{c}(1000) \\
(72)\end{array}$ & $\begin{array}{l}\text { Hot } \\
\text { MM-40 Exocet } \\
\text { MM-40 Exocet } \\
\text { ASPIDE }\end{array}$ & $\begin{array}{l}\text { Misil antitanque } \\
\text { Misiles buque-buque } \\
\text { y superficie-buque. } \\
\text { " " } \\
\text { Misiles aire-aire, tie- } \\
\text { rra-aire, buque-aire }\end{array}$ & $\begin{array}{l}1980 \\
1980 \\
(1980)\end{array}$ & $\begin{array}{l}1980-84 \\
1988 \\
1985 \\
1983\end{array}$ & $\begin{array}{l}200 \text { por afio } \\
(12) \\
(30) \\
48\end{array}$ & $\begin{array}{l}\text { Para armar } 6 \text { fragatas Mgko. } \\
\text { Destinada a cuatro destroyer. } \\
\text { MEko. }\end{array}$ \\
\hline
\end{tabular}




\begin{tabular}{|c|c|c|c|c|c|c|c|}
\hline Pais & $\begin{array}{l}\text { Canti- } \\
\text { dad }\end{array}$ & Tipo de arma & Descripción & $\begin{array}{l}\text { Afío de } \\
\text { orden }\end{array}$ & $\begin{array}{l}\text { Año } \\
\text { entrega }\end{array}$ & $\begin{array}{l}\text { Cantidad } \\
\text { entregada }\end{array}$ & Comentarios \\
\hline COLOMBIA & $\begin{array}{l}(32) \\
(240) \\
(64)\end{array}$ & $\begin{array}{l}\text { MM-40 Exocet } \\
\text { AIM-7F Sparrow } \\
\text { Seasparrow }\end{array}$ & $\begin{array}{l}\text { Buque-buque } \\
\text { Misiles aire-aire. } \\
\text { Misiles buque-buque }\end{array}$ & $\begin{array}{l}(1980) \\
1982 \\
1980\end{array}$ & $\begin{array}{l}1983 \\
1984 \\
1983 \\
1984 \\
1988 \\
1984\end{array}$ & $\begin{array}{c}16 \\
16 \\
(120) \\
(20) \\
(32) \\
(32)\end{array}$ & Рага armar cuatro fragatas. \\
\hline \multirow[t]{2}{*}{ ECUADOR } & 86 & MM-4 Exocet & $\begin{array}{l}\text { Misiles buque-buque } \\
\text { aire-buque }\end{array}$ & 1979 & $\begin{array}{l}1982 \\
1988\end{array}$ & $\begin{array}{c}(18) \\
(6)\end{array}$ & \\
\hline & 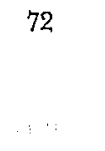 & ASPIDE & $\begin{array}{l}\text { Misiles aire-aire, tie- } \\
\text { rra-aire y buque- } \\
\text { buque. }\end{array}$ & 1979 & $\begin{array}{l}1982 \\
1983\end{array}$ & $\begin{array}{c}(24) \\
(36)\end{array}$ & $\begin{array}{l}\text { Para armar seis corbetas tipo } \\
\text { Esmeralda. }\end{array}$ \\
\hline PARAGUAY & - & $\longrightarrow$ & $\longrightarrow$ & - & - & - & \\
\hline \multirow[t]{4}{*}{ PERU } & 40 & AM-39 Exocet & Misil aire-buque & 1982 & & & $\begin{array}{l}\text { Para armar los Mirage } 2000 \text {, } \\
\text { Posible congelación en } 50 \% \text {. }\end{array}$ \\
\hline & 96 & ASPIDE & $\begin{array}{l}\text { Misiles aire-aire, tie- } \\
\text { ma-aire y buque- } \\
\text { buque. }\end{array}$ & 1975 & $\begin{array}{l}1979 \\
1984\end{array}$ & $\begin{array}{l}48 \\
(24)\end{array}$ & $\begin{array}{l}\text { Para armar } 4 \text { fragatas tipo } \\
\text { LuPo. }\end{array}$ \\
\hline & & & & 1974 & $\begin{array}{l}1979 \\
1984-85\end{array}$ & $\begin{array}{l}(48) \\
(48)\end{array}$ & \\
\hline & 96 & OTOMAT 1 & Misiles buque-buque. & & & & $\begin{array}{l}\text { Para armar } 4 \text { fragatas tipo } \\
\text { LUPo. }\end{array}$ \\
\hline VENEZUELA & (60) & ROLAND-2 & Misil móvil tierra-aire & & 1982 & & Defensa antiaérea. \\
\hline
\end{tabular}

Guadro confeccionado por el autor: Sipry Yearbook de 1985. 
ANEXO 1 - REGISTRO DE LAS PRINGIPALES TRANSACCIONES DE AMERIGA DEL SUR - 1984

(Muestra las armas cuya compra ha sido ordenada o está en proceso de entrega)

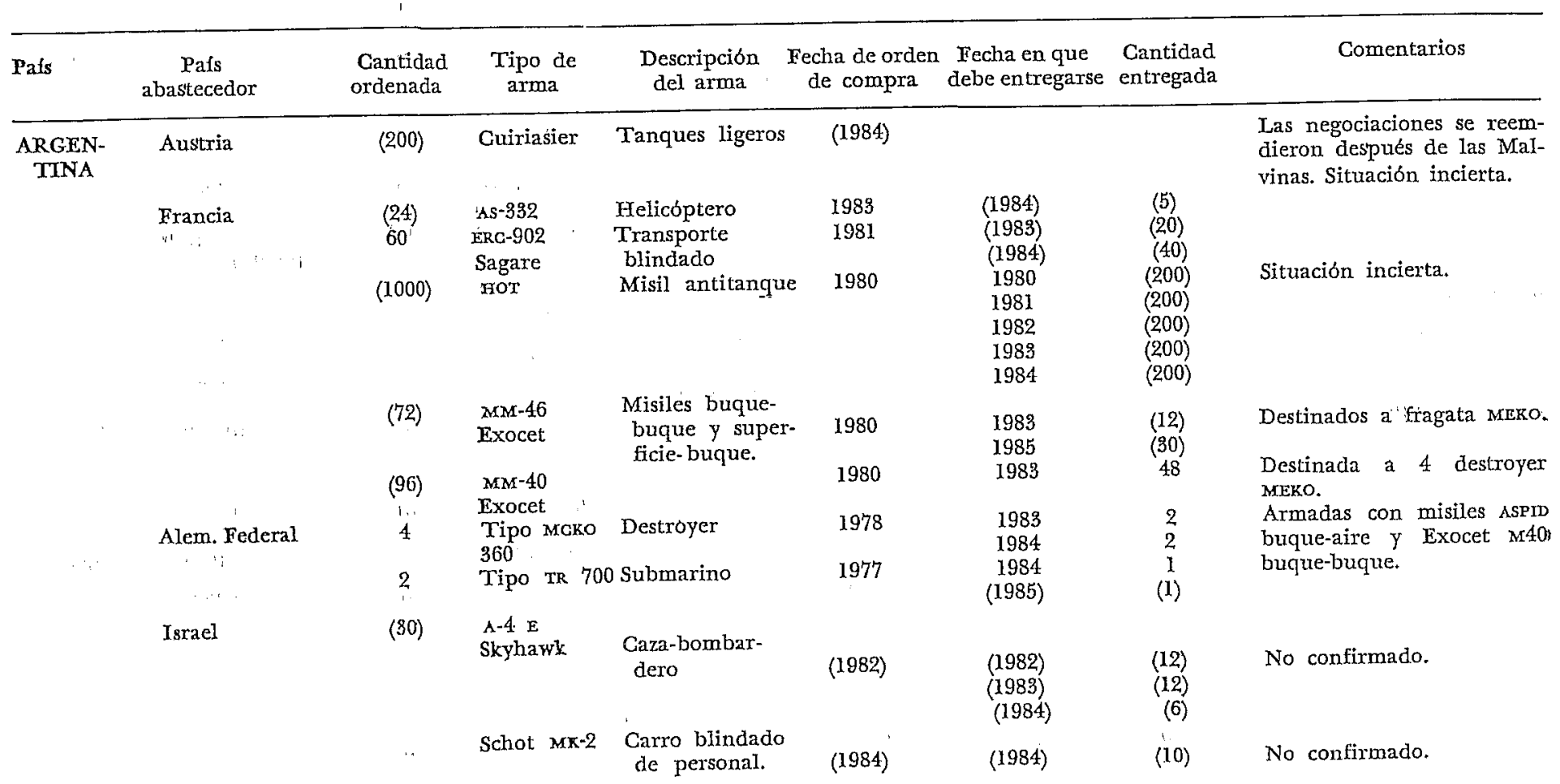




\begin{tabular}{|c|c|c|c|c|c|c|c|c|}
\hline Pals & $\begin{array}{c}\text { País } \\
\text { al bastecedor }\end{array}$ & $\begin{array}{l}\text { Cantidad } \\
\text { ordenada }\end{array}$ & $\begin{array}{l}\text { Tipo de } \\
\text { arma }\end{array}$ & $\begin{array}{l}\text { Descripción } \\
\text { del arma }\end{array}$ & $\begin{array}{l}\text { Fecha de orden } \\
\text { de compra }\end{array}$ & $\begin{array}{l}\text { Fecha en que } \\
\text { debe entregarse }\end{array}$ & $\begin{array}{l}\text { Cantidad } \\
\text { entregada }\end{array}$ & Comentarios \\
\hline & Italia & $\begin{array}{l}2 \\
(15) \\
(96)\end{array}$ & $\begin{array}{l}\text { s.61 R } \\
\text { Palmarie } 1 \\
\text { Aspide } \\
\end{array}$ & $\begin{array}{l}\text { Helicóptero au- } \\
\text { 155 topropulsado. } \\
\text { Misiles aire- } \\
\text { aire } \\
\text { tierra-aire } \\
\text { buque-aire } \\
\end{array}$ & $\begin{array}{r}(1983) \\
1988 \\
(1979)\end{array}$ & $\begin{array}{r}(1984) \\
1988 \\
1984 \\
\end{array}$ & $\begin{array}{l}(2) \\
48 \\
48 \\
\end{array}$ & $\begin{array}{l}\text { Posiblemente para ser adap- } \\
\text { tadas a los TAM. }\end{array}$ \\
\hline & España & 12 & c-212-200 & Transporte & 1984 & & & \\
\hline$\overline{\text { BOLIVIA }}$ & $\begin{array}{l}\text { Brasil } \\
\text { Francia }\end{array}$ & $\begin{array}{r}3 \\
12 \\
18\end{array}$ & $\begin{array}{l}\text { GB-315 B } \\
\text { GAVAIO } \\
\text { MIRAGE } 50 \\
\text { T } 33 \text { A }\end{array}$ & $\begin{array}{l}\text { Helicópteros } \\
\text { Caza/MRCA } \\
\text { Aviones de } \\
\text { entrenamiento. }\end{array}$ & $\begin{array}{r}1984 \\
(1984) \\
(1984) \\
\end{array}$ & 1984 & 3 & $\begin{array}{l}\text { No confirmado. } \\
\text { Costo } \$ 6.2 \mathrm{~mm} \text {. }\end{array}$ \\
\hline BRASIL & $\begin{array}{l}\text { Australia } \\
\text { Canadá } \\
\text { Francia } \\
\text { Alem. Federal } \\
\text { Italia } \\
\text { EE. UU. }\end{array}$ & $\begin{array}{c}12 \\
12 \\
2 \\
(48) \\
1 \\
(6) \\
1\end{array}$ & $\begin{array}{l}\text { A-4G Skyhaw } \\
\text { DHC-50 } \\
\text { Búfalo. } \\
\text { MIRAGE-50 } \\
\text { MM-40 } \\
\text { Exocet } \\
\text { Tipo } 209 / 3 \\
\text { sH-30 Sea } \\
\text { King. } \\
\text { HS-125 } \\
\text { UM-60A } \\
\text { LUTP-7 Al }\end{array}$ & $\begin{array}{l}\text { awk Caza- } \\
\text { bombardero } \\
\text { Aviones de } \\
\text { transporte. } \\
\text { Entrenamiento } \\
\text { Misiles buque.. } \\
\text { a buque } \\
\text { Submarino } \\
\text { Helicóptero } \\
\text { Avión } \\
\text { transporte. } \\
\text { Helicóptero } \\
\text { Vehiculos anfi- } \\
\text { bios de asalto. } \\
\end{array}$ & $\begin{array}{l}(1983) \\
(1983) \\
(1982) \\
1984 \\
1982 \\
(1982)\end{array}$ & 1984 & 2 & $\begin{array}{l}\text { No confirmado. } \\
\text { No confirmado. } \\
\text { Para armar } 4 \text { corbetas y } 2 \\
\text { fragatas. }\end{array}$ \\
\hline CHOXE & $\begin{array}{l}\text { Brasil } \\
\text { Francia } \\
\text { Alem. Federal } \\
\text { Gran Bretaña }\end{array}$ & $\begin{array}{c}1 \\
3 \\
2 \\
(18) \\
6\end{array}$ & $\begin{array}{l}\text { EMB-120 } \\
\text { MIRAGE-30 } \\
\text { MIRAGE-50 } \\
\text { Tipo 209/3 } \\
\text { Jaguar } \\
\text { Lijnx }\end{array}$ & $\begin{array}{l}\text { Aviones } \\
\text { transporte. } \\
\text { Entrenamiento } \\
\text { Caza/MrCA. ... } \\
3 \text { Submarinos. } \\
\text { Gaza } \\
\text { Helicóptero }\end{array}$ & $\begin{array}{c}(1982) \\
1984 \\
(1984) \\
1980 \\
(1985) \\
(1985)\end{array}$ & $\begin{array}{l}1984 \\
1984\end{array}$ & 1 & $\begin{array}{l}\text { No confirmado. } \\
\text { En negociación. } \\
\text { En negociación. }\end{array}$ \\
\hline
\end{tabular}




\begin{tabular}{|c|c|c|c|c|c|c|c|c|}
\hline Paiss & $\begin{array}{c}\text { Pais } \\
\text { abastecedor }\end{array}$ & $\begin{array}{l}\text { Cantidad } \\
\text { ordenada }\end{array}$ & Tipo de arma & $\begin{array}{c}\text { Descripción } \\
\text { del arma }\end{array}$ & $\begin{array}{c}\text { Fecha de orden } \\
\text { de compra }\end{array}$ & $\begin{array}{l}\text { Fecha en que } \\
\text { debe entregarse }\end{array}$ & $\begin{array}{l}\text { Cantidad } \\
\text { cntregada }\end{array}$ & Comentarios \\
\hline & EE. UU. & $\begin{array}{c}(100) \\
(8) \\
- \\
(16)\end{array}$ & $\begin{array}{l}\text { Centauros } \\
\text { MM-88Exocet } \\
\text { Rapier } \\
\text { Seacat } \\
\quad \text { County Class } \\
\text { King An c-90 } \\
\end{array}$ & $\begin{array}{l}\text { Transportes blindados } \\
\text { de personal. } \\
\text { Misiles buque-buque } \\
\text { Misiles móviles tie- } \\
\text { rra-aire. } \\
\text { Misiles buque-aire y } \\
\text { buque-buque. } \\
\text { Destroyer } \\
\text { Entrenamiento. }\end{array}$ & $\begin{array}{c}1985 \\
1981 \\
(1985) \\
1981 \\
1981 \\
(1984)\end{array}$ & $\begin{array}{c}1982 \\
1984 \\
1982 \\
(1984)\end{array}$ & $\begin{array}{c}(8) \\
(8) \\
1 \\
1 \\
\end{array}$ & $\begin{array}{l}\text { Licencia de export. en reserva. } \\
\text { Para armar dos destroyer. } \\
\text { Para armar dos destroyer. } \\
\text { En negociación. } \\
\text { Para armar dos destroyer. }\end{array}$ \\
\hline GOLOMBIA & $\begin{array}{l}\text { Australia } \\
\text { Brasil } \\
\text { Francia } \\
\text { Alem. Fed. }\end{array}$ & $\begin{array}{c}2 \\
5 \\
(10) \\
(15)\end{array}$ & 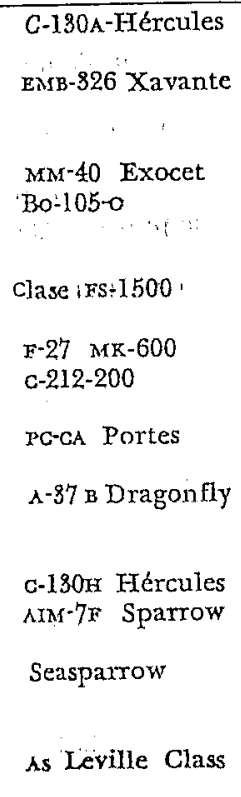 & $\begin{array}{l}\text { Helicóptero de } \\
\text { transporte. } \\
\text { Aviones de entrena- } \\
\text { miento Contra In- } \\
\text { surgencia. } \\
\text { Buque-buque } \\
\text { Helicópteros , } \\
\text { Fragatas. } \\
\text { Transporte. } \\
\text { Aviones de } \\
\text { transporte. } \\
\text { Aviones de } \\
\text { transporte. } \\
\text { Aviones de } \\
\text { combate. } \\
\text { Contra Insurgencia. } \\
\text { Avión de transporte. } \\
\text { Misiles aire-aire. } \\
\text { Misiles buque- } \\
\text { buque. } \\
\text { Fragatas. }\end{array}$ & $\begin{array}{l}1980 \\
(1984) \\
1984 \\
1984 \\
1982 \\
\\
(1983) \\
1982\end{array}$ & $\begin{array}{l}(1983) \\
(1984) \\
1984 \\
1983 \\
1984 \\
\\
1983 \\
1984 \\
1982 \\
1984\end{array}$ & $\begin{array}{l}(12) \\
(3) \\
8 \\
(120) \\
(120) \\
(32) \\
(32) \\
2 \\
2\end{array}$ & $\begin{array}{l}\text { No confirmado. } \\
\text { Para armar } 4 \text { fragatas Es-1500. } \\
\text { Para armar } 4 \text { fragatas Es-1500. } \\
\therefore \text {." } \\
\text { No confirmado. }\end{array}$ \\
\hline
\end{tabular}




\begin{tabular}{|c|c|c|c|c|c|c|c|c|}
\hline Pafo & $\begin{array}{c}\text { Pals } \\
\text { abastecedor }\end{array}$ & $\begin{array}{l}\text { Cantidad } \\
\text { ordenada }\end{array}$ & Tipo de arma & $\begin{array}{c}\text { Descripción } \\
\text { del arma }\end{array}$ & $\begin{array}{l}\text { Fecha de orden } \\
\text { de compra }\end{array}$ & $\begin{array}{l}\text { Fecha en que } \\
\text { debe entregarse }\end{array}$ & $\begin{array}{l}\text { Cantidad } \\
\text { entregada }\end{array}$ & Comentarios \\
\hline \multirow[t]{6}{*}{ EGUADOR } & Francia & $\begin{array}{l}10 \\
36\end{array}$ & $\begin{array}{l}\text { As } 332 \\
\text { MM-40 Exocet }\end{array}$ & $\begin{array}{l}\text { Helicópteros. } \\
\text { Buque-buque } \\
\text { aure }\end{array}$ & $\begin{array}{l}1982 \\
1979\end{array}$ & \multirow[t]{2}{*}{$\begin{array}{l}1982 \\
1982 \\
1983 \\
1984\end{array}$} & \multirow{2}{*}{$\begin{array}{c}(3) \\
(12) \\
(18) \\
(6)\end{array}$} & $\begin{array}{l}\text { Incierto. } \\
\text { Para armar } 6 \text { corbetas tipo } \\
\text { Esmeralda. }\end{array}$ \\
\hline & \multirow[t]{3}{*}{$\begin{array}{l}\text { Israel } \\
\text { Italia }\end{array}$} & \multirow[t]{2}{*}{$\begin{array}{c}12 \\
(72)\end{array}$} & \multirow[t]{2}{*}{$\begin{array}{l}\text { Kfir-c? } \\
\text { Aspide }\end{array}$} & \multirow{2}{*}{$\begin{array}{l}\text { Avión Caza/MrGa } \\
\text { Misiles aire-aire, } \\
\text { tierra-aire y } \\
\text { buque-buque. }\end{array}$} & \multirow[t]{2}{*}{1979} & & & $\begin{array}{l}\text { Aprobado por EE. UU., operan } \\
\text { para } 12 \text { mm. }\end{array}$ \\
\hline & & & & & & \multirow{3}{*}{$\begin{array}{c}1982 \\
1983 \\
(1984) \\
1982 \\
1983 \\
1984\end{array}$} & \multirow{3}{*}{$\begin{array}{c}(24) \\
(36) \\
(12) \\
2 \\
3 \\
1\end{array}$} & $\begin{array}{l}\text { Para armar } 6 \text { corbetas tipo } \\
\text { Esmeralda. }\end{array}$ \\
\hline & & 6 & Nave Esmeralda & $s$ Corbetas. & 1979 & & & \\
\hline & \multirow[t]{2}{*}{ EE. UU. } & \multirow[t]{2}{*}{1} & \multirow[t]{2}{*}{$\mathbf{x}-100-30$} & Avión de & & & & \\
\hline & & & & transporte. & 1982 & 1984 & 1 & \\
\hline \multirow{2}{*}{ PARAGUAY } & Brasil & $\stackrel{(10)}{-}$ & $\begin{array}{l}\text { EMB-110 } \\
\text { EE-11 Urutu }\end{array}$ & $\begin{array}{l}\text { Avión de transporte. } \\
\text { Carro blindado }\end{array}$ & $(1985)$ & & & \multirow{2}{*}{$\begin{array}{l}\text { En negociación. } \\
\text { Número no especificado. } \\
\text { Denominación Paraguaya. }\end{array}$} \\
\hline & España & $\begin{array}{l}1 \\
2 \\
\end{array}$ & $\begin{array}{l}\text { Clase Rorafma } \\
\text { c-212-200 }\end{array}$ & $\begin{array}{l}\text { de transporte. } \\
\text { Carro personal. } \\
\text { Avión de transporte. }\end{array}$ & $\begin{array}{r}(1984) \\
1983 \\
1984 \\
\end{array}$ & $(1985)$ & (1) & \\
\hline \multirow[t]{6}{*}{ PERU } & \multirow[t]{2}{*}{$\begin{array}{l}\text { Argentina } \\
\text { Francia }\end{array}$} & $\begin{array}{l}80 \\
26\end{array}$ & $\begin{array}{l}\text { TAMI } \\
\text { Mirage-2000 }\end{array}$ & $\begin{array}{l}\text { Tanque mediano. } \\
\text { Caza/Bombardero. }\end{array}$ & $\begin{array}{c}(1985) \\
1982\end{array}$ & & & $\begin{array}{l}\text { En negociación. } \\
\text { El Presidente anunció que la } \\
\text { compra se reducirfa a 13. }\end{array}$ \\
\hline & & (26) & Mirage-5 & Caza & 1981 & $\begin{array}{c}1984 \\
(1985)\end{array}$ & $\begin{array}{l}(13) \\
(13)\end{array}$ & Posible Mirage 50 \\
\hline & \multirow[t]{3}{*}{ Italía } & \multirow[t]{2}{*}{$\begin{array}{c}40 \\
4 \\
96\end{array}$} & \multirow[t]{2}{*}{$\begin{array}{l}\text { AM-39 Exocet } \\
\text { SH-30 Sea King } \\
\text { Aspide }\end{array}$} & \multirow{2}{*}{$\begin{array}{l}\text { Misil aire-buque, } \\
\text { Helicóptero. } \\
\text { Misil aire-aire } \\
\text { tierra-aire } \\
\text { buque-buque. }\end{array}$} & $\begin{array}{c}1982 \\
(1984)\end{array}$ & & & \multirow[t]{2}{*}{ Para armar los Mirage 2000.} \\
\hline & & & & & 1975 & $\begin{array}{c}1979 \\
1984 \\
1985\end{array}$ & $\begin{array}{l}48 \\
(24) \\
(24)\end{array}$ & \\
\hline & & 96 & \multirow[t]{2}{*}{ Otomat-1 } & Misiles buque- & & & & \multirow[t]{2}{*}{ Para armar fragatas tipo LuPo. } \\
\hline & xE. UV, & 0 & & Helicóptero. & 1974 & $\begin{array}{l}1979 \\
1984 \\
1985 \\
1983 \\
1984\end{array}$ & $\begin{array}{l}4.3 \\
(24) \\
(24) \\
(3) \\
(3)\end{array}$ & \\
\hline
\end{tabular}




\begin{tabular}{|c|c|c|c|c|c|c|c|c|}
\hline País & $\begin{array}{c}\text { Pals } \\
\text { abastecedor }\end{array}$ & $\begin{array}{l}\text { Cantidad } \\
\text { ordenada }\end{array}$ & Tipo de arma & $\begin{array}{l}\text { Descripción } \\
\text { de arma }\end{array}$ & $\begin{array}{l}\text { Fecha de orden } \\
\text { de compra }\end{array}$ & $\begin{array}{l}\text { Fecha en que } \\
\text { debe entregarse }\end{array}$ & $\begin{array}{l}\text { Cantidad } \\
\text { entregada }\end{array}$ & Comentarios \\
\hline & URSS & (12) & Mi 24 Hind-D & Helicóptero & (1984) & & & \\
\hline \multirow[t]{11}{*}{$\begin{array}{l}\text { VENE- } \\
\text { ZUELA }\end{array}$} & Argentina & 24 & IA-58-A-Pucará & $\begin{array}{l}\text { Avión de Contra } \\
\text { Insurgencia }\end{array}$ & 1983 & & & $\begin{array}{l}\text { Entrega programada para } \\
1985-86 .\end{array}$ \\
\hline & Brasil & 30 & $\mathrm{EE}-1 \mathrm{I}$ Uruta & $\begin{array}{l}\text { Transporte blindado } \\
\text { de personal. }\end{array}$ & 1983 & 1984 & 30 & \\
\hline & Francia & $\overrightarrow{(60)}$ & $\begin{array}{l}\text { AMx-13-90 } \\
\text { Roland-2 }\end{array}$ & $\begin{array}{l}\text { Tanque ligero. } \\
\text { Misil Móvil tie- } \\
\text { Ira-aire }\end{array}$ & $\begin{array}{l}(1985) \\
(1982)\end{array}$ & & & $\begin{array}{l}\text { En negociación por algunas } \\
\text { docenas. } \\
\text { Aproximadamente } 10 \text { uni- } \\
\text { dades de lanzamiento. }\end{array}$ \\
\hline & Alem. Fed. & 10 & Tp2-1 & $\begin{array}{l}\text { Transporte blindado } \\
\text { de personal. }\end{array}$ & (1983) & $\begin{array}{l}(1988) \\
(1984)\end{array}$ & $\begin{array}{l}(5) \\
(5)\end{array}$ & No confirmado. \\
\hline & Italia & $\begin{array}{l}10 \\
8\end{array}$ & $\begin{array}{l}\text { A-109 Hcruds } \\
\text { G } 222\end{array}$ & $\begin{array}{l}\text { Helicóptero } \\
\text { Aviones de } \\
\text { Transporte }\end{array}$ & $\begin{array}{r}1984 \\
(1982)\end{array}$ & 1983 & (4) & \\
\hline & & $\begin{array}{l}8 \\
4 \\
5\end{array}$ & $\begin{array}{l}\text { G } 222 \\
\text { s-61R } \\
\text { Tipo } 42 M\end{array}$ & $\begin{array}{l}\text { Transporte } \\
\text { Helicóptero } \\
\text { Patrulleras }\end{array}$ & $\begin{array}{c}(1985) \\
(1984) \\
1983\end{array}$ & $\begin{array}{l}1984 \\
1984\end{array}$ & (4) & En negociación. \\
\hline & Surcorea & (6) & Tipo Tacama & $\begin{array}{l}\text { Buques de des- } \\
\text { embarco }\end{array}$ & 1982 & $\begin{array}{l}1984 \\
1985\end{array}$ & $\begin{array}{c}4 \\
(2)\end{array}$ & \\
\hline & EE. UU. & 2 & $\mathrm{c}-130 \mathrm{x}-3$ & $\begin{array}{l}\text { Helicóptero de } \\
\text { transporte. }\end{array}$ & 1981 & & & \\
\hline & & $\begin{array}{c}18 \\
6\end{array}$ & $\begin{array}{l}F-16 \AA \\
F-16 B\end{array}$ & $\begin{array}{l}\text { Cazabombardero. } \\
\text { Entrenamiento }\end{array}$ & 1981 & 1983 & (3) & $\begin{array}{l}\$ 500 \mathrm{~mm} . \text { costo total de } \\
\text { los } 29 \mathrm{~F}-16 .\end{array}$ \\
\hline & & I & & de caza. & 1981 & 1983 & (3) & \\
\hline & & 1 & Guystram-3 & Buque-transporte. & $(1983)$ & $(1984)$ & 1 & \\
\hline
\end{tabular}

Confeccionado por el autor: Datos Sipri Yearbook - 1985. 